CONGENITAL HEART DISEASE

\title{
Balloon aortic valvoplasty in paediatric patients: progressive aortic regurgitation is common
}

\author{
C Balmer, M Beghetti, M Fasnacht, B Friedli, U Arbenz
}

Heart 2004;90:77-81

See end of article for authors' affiliations ....................

Correspondence to: Dr C Balmer, University Children's Hospital, Steinwiesstrasse $75, \mathrm{CH}$ 8032 Zurich, Switzerland; christian.balmer@kispi. unizh.ch

Accepted

19 September 2003
Objective: To evaluate immediate and midterm results after balloon valvoplasty in a paediatric population with congenital aortic stenosis, giving special consideration to aortic regurgitation.

Design: Retrospective study.

Setting: Two tertiary referral centres for paediatric cardiology.

Patients: 70 consecutive patients, with an age range of $0-16.4$ years. Group A infants $<3$ months old $(n=21)$. Group B children $>3$ months old $(n=49)$. Median follow up time was 19.8 months, range $0-$ 158 months.

Intervention: All patients underwent balloon aortic valvoplasty. The balloon to annulus ratio was selected at a mean of 0.90 (range $0.67-1.0$ ).

Main outcome measures: Doppler gradients and degree of aortic regurgitation.

Results: The pressure gradient dropped significantly with the intervention and increased mildly at follow up. Freedom from relevant aortic regurgitation (that is, moderate and severe) was initially lower in group A $(75 \% \vee 90 \%$ after one month) but after two years the difference between the two groups was not significant (50\% v 61\%). Freedom from reintervention was significantly lower in group A (with $35 \%$ v $80 \%$ ) after three years.

Conclusion: Aortic balloon valvoplasty is safe and effective but has a high rate of early reintervention in infants with critical aortic stenosis. The major long term problem is progressive aortic regurgitation, which does not seem to be prevented by the use of small balloons.
A ortic balloon valvoplasty has now become established as an alternative to surgery for the long term palliation of congenital aortic stenosis in children. However, residual stenosis and the occurrence of aortic regurgitation are well known problems after balloon valvoplasty, as well as after surgery. ${ }^{12}$ While residual stenosis has little influence on future surgical options, balloon valvoplasty induced aortic regurgitation is often the result of commissural avulsion, cusp dehiscence, and cusp tear or perforation and it can make further surgical reinterventions more difficult. ${ }^{3}{ }^{4}$ Oversized balloons are a risk factor for aortic regurgitation. ${ }^{5-8}$ The purpose of this study was to evaluate the results of balloon aortic valvoplasty in two paediatric cardiology centres where no oversized balloons were used. We focused on the transvalvar gradient and on the occurrence and progression of aortic regurgitation in the medium and long term follow up.

\section{METHODS}

\section{Patients}

This was a retrospective study of 70 consecutive children with congenital aortic stenosis who underwent balloon valvoplasty between December 1985 and August 1999 at two tertiary paediatric cardiology care centres. On account of the different clinical presentation, risks, and outcome, two age groups were formed for evaluation (table 1). All patients in group A were in a critical clinical condition with severe heart failure. In all of the group A patients one or more of the following four criteria were fulfilled: need of ventilatory support; need of inotropes; need of prostaglandins for maintenance of ductus patency; and severely impaired left ventricular function in two dimensional echocardiography. In group B, four patients had undergone previous surgical aortic valvotomy.
All patients had had a complete echocardiographic examination the day before the intervention. The degree of the stenosis was assessed by continuous wave Doppler ultrasound. The valve morphology was analysed by means of two dimensional echocardiography. There were 17 tricommissural, 51 bicommissural, and two monocommissural aortic valves. One patient (four months of age) was excluded from this study because the attempted balloon valvoplasty was not technically feasible. There were no patients with significant subaortic stenosis.

The indication for balloon valvoplasty was the presence of clinical symptoms and an ECG strain pattern, a peak Doppler gradient higher than 70 , or a mean gradient higher than $40 \mathrm{~mm} \mathrm{Hg}$ in the absence of symptoms, with at most mild aortic regurgitation. In children with critical aortic stenosis and heart failure, balloon valvoplasty was performed irrespective of their Doppler gradients.

All but seven procedures were conducted under general anaesthesia. We used a retrograde transcutaneous femoral approach $^{7}$ in all but one patient, for whom an axillary approach was used on account of coarctation. The left ventricular-aortic junction was measured at the hinge point of the valve leaflet by means of echocardiography and angiography. The balloon to annulus ratio was intended to be less than 1.0 and ranged from $0.67-1.0$, with a mean (SD) of 0.9 (0.07). Peak to peak pressure gradients and supraaortic and left ventricular angiograms were obtained before and after dilatation. Aortic regurgitation was graded by means of angiography from 0 to 5 as described by Hunt and colleagues $^{9}$ and by means of echocardiography as none, mild, moderate, and severe as described below. The mean (SD) fluoroscopy time was 32 (14) minutes.

The median follow up was 19.8 months, with a range of 0-158 months. Complete echocardiographic re-evaluation was performed the day after the intervention and at least 
Table 1 Number of patients in each group and age in days (d), months $(m)$, and years ( $y$ )

\begin{tabular}{llll}
\hline & Group A & Group B & All patients \\
\hline Number of patients & 21 & 49 & 70 \\
Median age & $7 \mathrm{~d}$ & $6.4 \mathrm{y}$ & $2.2 \mathrm{y}$ \\
Age range & $2 \mathrm{~d}-2.8 \mathrm{~m}$ & $3.2 \mathrm{~m}-16.4 \mathrm{y}$ & $2 \mathrm{~d}-16.4 \mathrm{y}$ \\
\hline
\end{tabular}

annually during follow up. All the echocardiographic measurements up to the time of reintervention were included in the study.

\section{Echocardiography}

In patients with normal left ventricular function, the severity of aortic stenosis was graded according to Doppler gradient measurements. The stenosis was considered to be severe if the maximum Doppler gradient was $>70 \mathrm{~mm} \mathrm{Hg}$ or the mean gradient $>40 \mathrm{~mm} \mathrm{Hg}$. If the maximum gradient was between $50-70 \mathrm{~mm} \mathrm{Hg}$ or the mean gradient between 25$40 \mathrm{~mm} \mathrm{Hg}$, the stenosis was considered to be moderate. If the maximum gradient was $<50 \mathrm{~mm} \mathrm{Hg}$ and the mean gradient $<25 \mathrm{~mm} \mathrm{Hg}$, the stenosis was considered to be mild. ${ }^{10-15}$

The severity of aortic regurgitation was also assessed echocardiographically. ${ }^{16}$ Mild aortic regurgitation was defined by the colour jet ending proximal to the tip of the anterior mitral valve leaflet, jet width $<30 \%$ of the left ventricular outflow tract diameter, pressure half time $>600 \mathrm{~ms}$, and end diastolic retrograde flow in the descending thoracic aorta $<20 \mathrm{~cm} / \mathrm{s}$. Moderate aortic regurgitation was defined by the colour jet ending distal to the mitral valve, jet width $>30 \%$ of the left ventricular outflow tract diameter, pressure half time $<600 \mathrm{~ms}$, end diastolic retrograde flow in the descending thoracic aorta $20-40 \mathrm{~cm} / \mathrm{s}$, pandiastolic retrograde flow in the abdominal aorta, and dilated left ventricle. Severe aortic regurgitation was defined by the colour jet length and width, pressure half time, and flow pattern in the abdominal aorta as described for grade 2 , plus end diastolic retrograde flow in the descending thoracic aorta $>40 \mathrm{~cm} / \mathrm{s}$ and a moderately to severely dilated left ventricle.

\section{Statistical analysis}

Groups were compared by the unpaired $t$ test, assuming equal variances. Survival and freedom from reinterventions were estimated with the Kaplan Meier equation, followed by a log rank test. The difference between the two groups was significant when $\mathrm{p}<0.05$.

\section{IMMEDIATE RESULTS Gradient relief}

In both groups, the peak to peak catheter gradient and instantaneous Doppler gradient were significantly reduced. The invasively measured peak to peak gradient was reduced from a mean (SD) of 80 (26) $\mathrm{mm} \mathrm{Hg}$ to 32 (16) $\mathrm{mm} \mathrm{Hg}$ $(\mathrm{p}<0.001)$ in group A and from 68 (27) $\mathrm{mm} \mathrm{Hg}$ to 29 (13) $\mathrm{mm} \mathrm{Hg}(\mathrm{p}<0.001)$ in group B. The maximal Doppler gradient decreased from a mean (SD) of 75 (25) $\mathrm{mm} \mathrm{Hg}$ to 45 (15) $\mathrm{mm} \mathrm{Hg}$ in group A $(\mathrm{p}<0.001)$ and from 88 (23) $\mathrm{mm} \mathrm{Hg}$ to 52 (17) $\mathrm{mm} \mathrm{Hg}$ in group B $(\mathrm{p}<0.001)$ (fig 1). The mean Doppler gradient decreased from a mean (SD) of 50 (16) $\mathrm{mm} \mathrm{Hg}$ to $27(10) \mathrm{mm} \mathrm{Hg}(\mathrm{p}<0.001)$ in group A and from 51 (16) $\mathrm{mm} \mathrm{Hg}$ to 30 (9) $\mathrm{mm} \mathrm{Hg}(\mathrm{p}<0.001)$ in group B. The residual aortic stenosis of the survivors of group A $(n=19)$ was severe in nine patients $(47 \%)$, moderate in four patients $(21 \%)$, and mild in six patients $(32 \%)$. In group $\mathrm{B}(\mathrm{n}=49)$ the respective values were six patients $(12 \%), 25$ patients $(51 \%)$, and 18 patients $(37 \%)$.

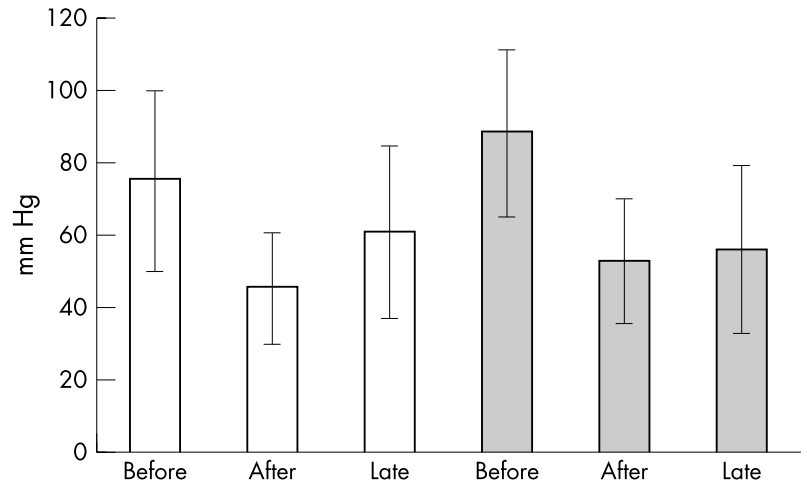

Figure 1 Instantaneous maximum Doppler gradient before and immediately after balloon valvoplasty and at latest follow up. Open columns: group $A$, infants $<3$ months old, $n=21$. Grey columns: group $B$, children $>3$ months old, $n=49$. Values are mean (SD).

\section{Aortic regurgitation}

Before the intervention, aortic regurgitation was absent or trivial (grade $0-1$ ) in all patients. Immediate postinterventional angiographic assessment of aortic regurgitation in group A was possible for 18 patients. Aortic regurgitation progressed to grade 2 in four patients and to grades 3, 4, and 5 in one patient each. In group B, grade 0 and 1 persisted in 34 of 49 patients. Postinterventional aortic regurgitation was considered to be grade 2 in 10 patients and grade 3 in five patients. Grades 4 and 5 did not occur in this group. Table 2 shows the results of the echocardiographic assessment of aortic regurgitation. Neither the balloon/annulus ratio, nor the age at the time of intervention, nor the valve morphology correlated with the occurrence of aortic regurgitation.

\section{Complications}

In group $\mathrm{A}$, the femoral artery was occluded in 12 patients $(57 \%)$, which was successfully treated by heparin in eight patients and by fibrinolysis in three patients, leaving one permanent occlusion. In group $\mathrm{B}$, the femoral artery was occluded in nine patients (18\%) and was successfully treated by heparin in six patients, by fibrinolysis in two patients, and by percutaneous transluminal angioplasty in one patient. A superficial femoral artery tear required surgical repair in one patient. During catheterisation ventricular fibrillation occurred in two patients of group A (one fatal) and in one patient of group B. Five patients in group B had a short nonsustained run of ventricular tachycardia. Two patients of each group had a sinus bradycardia (one fatal).

\section{Early death}

Two patients, two and 11 days old, died during the intervention of bradycardia and ventricular fibrillation, respectively. One neonate with severe congestive heart failure, who underwent balloon valvoplasty during the first day of life, died 24 hours after the balloon valvoplasty of severe congestive heart failure.

\section{LONG TERM RESULTS Doppler gradients}

The last available Doppler gradient at a median follow up time of 19.8 months (range $0-158$ months) showed a rise in the maximum Doppler gradient to a mean (SD) of 60 (23) $\mathrm{mm} \mathrm{Hg}$ in group A $(p<0.001$ compared with the immediate postdilatation value) and to $55(23) \mathrm{mm} \mathrm{Hg}$ in group B (insignificant compared with the immediate postinterventional measurement). The mean Doppler gradients at last follow up were a mean (SD) of 37 (20) $\mathrm{mm} \mathrm{Hg}$ in group 


\begin{tabular}{|c|c|c|c|c|c|}
\hline & None & Mild & Moderate & Severe & $\begin{array}{l}\text { Missing } \\
\text { assessment }\end{array}$ \\
\hline \multicolumn{6}{|l|}{ Group $\mathrm{A}:<3$ months old, $\mathrm{n}=21$} \\
\hline Before balloon valvoplasty & 19 & 2 & 0 & 0 & 0 \\
\hline Immediately after balloon valvoplasty & 5 & 10 & 2 & 1 & 3 \\
\hline At latest fóllow up & 3 & 8 & 6 & 1 & 3 \\
\hline \multicolumn{6}{|l|}{ Group B: $>3$ months old, $n=49$} \\
\hline Before balloon valvoplasty & 26 & 23 & 0 & 0 & \\
\hline Immediately after balloon valvoplasty & 14 & 29 & 6 & 0 & \\
\hline At latest follow up & 9 & 25 & 10 & 5 & \\
\hline
\end{tabular}

A $(p=0.04)$ and $31 \quad(15) \mathrm{mm} \mathrm{Hg}$ in group B (not significant).

\section{Aortic regurgitation}

From our follow up at a median of 19.8 months (range of 0158 months), the probability of the occurrence of moderate or severe aortic regurgitation was estimated by means of the Kaplan-Meier equation. We calculated an actuarial freedom from moderate and severe aortic regurgitation in group A of $75 \%$ after one month, $62 \%$ after one year, and $50 \%$ after two years and in group B of $90 \%$ after one month, $71 \%$ after one year, and $61 \%$ after two and three years (fig 2 ).

\section{Reinterventions}

There were $11(52 \%)$ reinterventions in group A $(\mathrm{n}=21)$ : six for severe residual aortic stenosis, one for severe aortic regurgitation, and four for severe aortic regurgitation and aortic stenosis. The interventions were repeat balloon valvoplasty in two patients, surgical aortic valvotomy in four patients, valve repair in two patients, and valve replacement in three patients (one aortic homograft and two Ross procedures). There were $13(26 \%)$ reinterventions in group B ( $\mathrm{n}=49$ ): nine for severe residual aortic stenosis (four valvar, three subvalvar, and two supravalvar stenoses), three for severe aortic regurgitation, and one for severe aortic stenosis and aortic regurgitation. The interventions were repeat balloon valvoplasty in three patients, surgical valvotomy in two, aortic valve repair in two, resection of supravalvar aortic stenosis in one, and valve replacement in five (aortic valve prosthesis in two, aortic homograft in one, and Ross procedure in two patients). Reinterventions were necessary at an earlier stage in group A than in group B. The actuarial freedom from reintervention at one, two, and three years was $55 \%, 44 \%$, and $35 \%$ in group $\mathrm{A}$, and $89 \%, 86 \%$, and

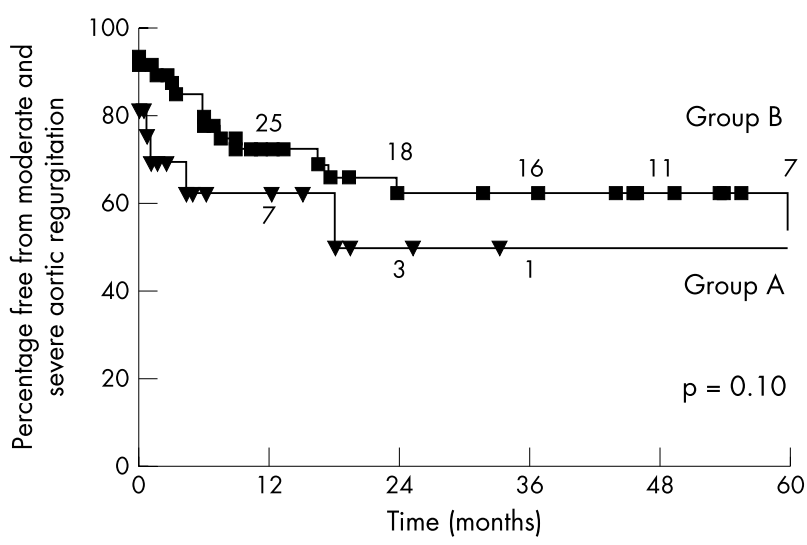

Figure 2 Freedom from moderate and severe aortic regurgitation in group $A$ (squares, $n=21$ ) and group $B$ (triangles, $n=49$ ).

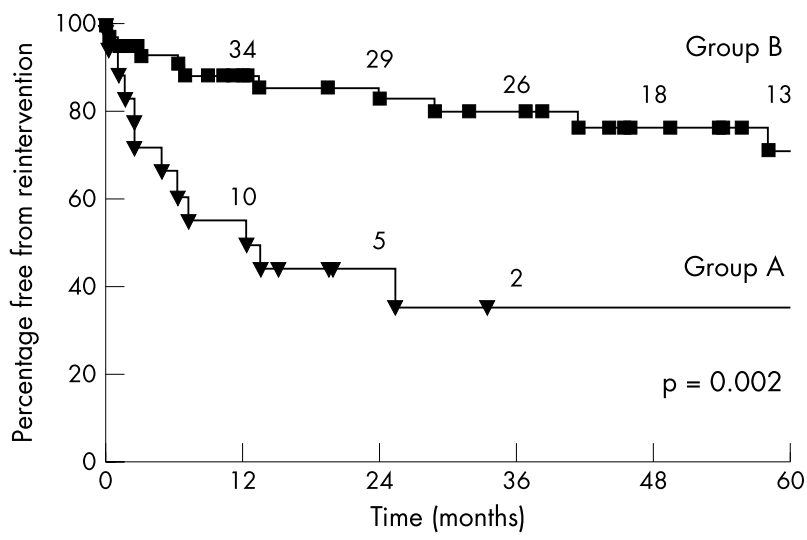

Figure 3 Freedom from reintervention in group $A$ (squares, $n=21$ ) and group $B$ (triangles, $n=49$ ).

$80 \%$ in group B, respectively, as calculated by the KaplanMeier equation (fig 3).

\section{Late death}

Four patients died later on during follow up: three in group A and one in group B. All the late deaths resulted from the progression of valvar heart disease and after surgical intervention: one after aortic valve reconstruction, one after mitral valve replacement for the treatment of endocarditis, one after the Konno procedure, and one after the Ross procedure at the age of three, six, and six months and 14 years, respectively.

\section{DISCUSSION}

The outcome of balloon aortic valvoplasty in our population in terms of immediate gradient reduction is comparable with that reported by others. ${ }^{15618-26}$ The selection of a moderate balloon size (balloon to annulus ratio $<1$ ) did not have a negative influence on gradient reduction. This is consistent with the registry study, which found no correlation between the balloon to annulus ratio (range 0.56-1.5) and the gradient reduction in 204 patients. ${ }^{1}$ Subsequently, gradients remained low for many years. These good results confirm the favourable and long lasting success of balloon aortic valvoplasty in reducing the left ventricular pressure load in the vast majority of patients of group B and, to a lesser extent, of group A. The significant increase of gradients in the newborn group during early follow up reflects recovery from an initially depressed ventricular function and not a decrease in valve area or restenosis. Balloon valvoplasty has a low procedure related mortality. All three early deaths occurred in neonates with severe congestive heart failure. Different results for the two age groups with regard to gradient relief and the progression of aortic valve regurgitation after balloon 
valvoplasty are most likely related to the valve morphology itself. In neonates and infants, stenotic aortic valves tend to be very dysmorphic, thickened, and myxomatous, whereas aortic stenosis in older patients is more often related to less dysmorphic and thinner valves with fusion of one or two commissures. ${ }^{27} 28$

Aortic regurgitation after balloon aortic valvoplasty is of major concern. The relation between oversized balloons and an increased incidence of postinterventional aortic regurgitation is well known. ${ }^{568}$ In an animal model, Helgason and colleagues $^{7}$ showed that, if the balloon to annulus ratio exceeded 1.2, there was significant damage to the aortic and mitral valve, as well as to the ventricular septum. We used 0.7 to 1.0 balloons and did not find any correlation between the balloon to annulus ratio and aortic regurgitation in this population. Even with the use of moderate sized balloons, the occurrence of aortic regurgitation immediately after balloon valvoplasty in our patients is in the same range as in other reports, ${ }^{161820212629}$ although the lack of standardised quantification and examiner dependent grading makes comparison difficult. If the incidence and degree of aortic regurgitation were low immediately after balloon valvoplasty, they did not remain so in the medium and long term follow up. Indeed, we showed by means of repeated Doppler measurements, which combined colour flow and pulsed wave Doppler criteria, that the course of aortic regurgitation is progressive. The combination of colour flow and pulsed wave Doppler criteria was a useful tool in evaluating postinterventional aortic regurgitation.

It is therefore not surprising that surgical reintervention was required as often for aortic regurgitation as for residual aortic stenosis in our study. However, aortic regurgitation clearly outweighed aortic stenosis as an indication for valve replacement.

Why aortic regurgitation progresses over time is not known. Inspection at surgery, if necessary, shows commissural avulsion, tearing, perforation, extensive scarring, and calcification of the aortic valve. ${ }^{34830}$ Tears, perforation, and partial detachment of the cusp with cusp prolapse may be explained by the procedure itself. ${ }^{8}$ Blood flow through the aortic valve leads to constant haemodynamic trauma of the valve tissue and may result in progressive tearing, scarring, retraction, and calcification of the valve, even in the absence of major residual stenosis.

The crucial point would be a comparison of balloon valvoplasty with the results of primary aortic valve surgery in the same patient population. The occurrence and progression of aortic regurgitation are documented after surgical valvotomy as well. ${ }^{11}{ }^{29-31}$ Unfortunately, quantitative data on aortic regurgitation after surgical valvotomy are practically non-existent. One study ${ }^{30}$ reported an incidence of 38\% for moderate to severe aortic regurgitation at 4.3 years' follow up after standard surgical valvotomy in 48 patients. However, the assessment of the degree of regurgitation in this study was based only on rough colour flow Doppler estimates, which precludes an accurate comparison with our data. To answer the question as to whether the low procedural risk and the low incidence of sequelae of balloon valvoplasty outweigh the advantage of possibly more valve preserving surgical valvotomy, it would be necessary to conduct a prospective randomised study.

\section{Conclusion}

Aortic balloon valvoplasty is safe and effective in the treatment of congenital aortic stenosis. In critical aortic stenosis of the neonate, the rate of early reintervention was quite high. In both age groups, significant aortic regurgitation at an early stage after balloon valvoplasty was uncommon, but progressive aortic regurgitation appears to be a major long term problem. Aortic valve replacement due to severe and progressive balloon valvoplasty induced aortic regurgitation was necessary in $10 \%$ of patients ( 7 of 70 ). The use of small balloons $(\leqslant 100 \%$ of the diameter of the aortic annulus) did not prevent late aortic regurgitation. Recognising that surgical valvotomy often gives good results and that the mortality rate in neonatal critical aortic stenosis has decreased in recent years, we believe that a randomised prospective study comparing surgery with balloon valvoplasty would be of major interest.

\section{Authors' affiliations}

C Balmer, M Fasnacht, U Arbenz, Paediatric Cardiology Units of the Children's University Hospital, Zurich, Switzerland

M Beghetti, B Friedli, University Hospital, Geneva, Switzerland

\section{REFERENCES}

1 Rocchini AP, Beekman RH, Ben Shachar G, et al. Balloon aortic valvuloplasty: results of the valvuloplasty and angioplasty of congenital anomalies registry. Am J Cardiol 1990;65:784-9.

2 Justo RN, McCrindle BW, Benson LN, et al. Aortic valve regurgitation after surgical versus percutaneous balloon valvotomy for congenital aortic valve stenosis. Am J Cardiol 1996;77:1332-8.

3 Hawkins JA, Minich LL, Shaddy RE, et al. Aortic valve repair and replacement after balloon aortic valvuloplasty in children. Ann Thorac Surg 1996:61:1355-8.

4 Bacha EA, Satou GM, Moran AM, et al. Valve-sparing operation for ballooninduced aortic regurgitation in congenital aortic stenosis. J Thorac Cardiovasc Surg 2001;122:162-8.

5 Sholler GF, Keane JF, Perry SB, et al. Balloon dilatation of congenital aortic valve stenosis. Circulation 1988;78:351-60.

6 Moore P, Egito E, Mowrey $\mathrm{H}$, et al. Midterm results of balloon dilatation of congenital aortic stenosis: predictors of success. J Am Coll Cardiol 1996;27:1257-63.

7 Helgason $\mathrm{H}$, Keane JF, Fellows KE, et al. Balloon dilation of the aortic valve: studies in normal lambs and in children with aortic stenosis. J Am Coll Cardiol 1987;9:816-22.

8 Philipps RR, Gerlis LM, Wilson N, et al. Aortic valve damage caused by operative balloon dilatation of critical aortic valve stenosis. Br Heart J 1987:57:168-70.

9 Hunt D, Baxley W, Kennedy J, et al. Quantitative evaluation of cineaortography in the assessment of aortic regurgitation. Am J Cardiol 1973:31:696-700.

10 Bengur AR, Snider AR, Serwer GA, et al. Usefulness of Doppler mean gradient in evaluation of children with aortic valve stenosis and comparison to gradient at catheterization. Am J Cardiol 1989;64:756-61

11 Weidman WH. Second natural history study of congenital heart defects. Circulation 1993;87(suppl 1):11-3.

12 Panidis IP, Mintz GS, Ross J. Value and limitations of Doppler ultrasound in the evaluation of aortic stenosis: a statistical analysis of 70 consecutive patients. Am Heart J 1986;1 12:150-8.

13 Wright SB, Wienecke MM, Meyer KB, et al. Correlation of paediatric echocardiographic Doppler and catheter-derived valvar aortic stenosis gradients and the influence of aortic regurgitation. Am J Cardiol 1996;77:663-5.

14 Kirklin JW, Barratt-Boyes BG. Congenital aortic stenosis. In: Kirklin JW, ed. Cardiac surgery. New York: Churchill Livingstone, 1993:1201.

15 Currie PJ, Seward JB, Reeder GS, et al. Continuous-wave Doppler echocardiographic assessment of severity of calcific aortic stenosis: a simultaneous Doppler-catheter correlative study in 100 adult patients. Circulation 1985;71:1162-9.

16 Tribouilloy C, Avinée P, Feng Shen W, et al. End diastolic flow velocity just beneath the aortic isthmus assessed by pulsed Doppler echocardiography: a new predictor of the aortic regurgitant fraction. Br Heart J 1991;65:37-40.

17 Snider AR. Quantification of aortic regurgitation. In: Snider AR, ed. Echocardiography in pediatric heart disease. St Louis: Mosby, 1997:180-6.

18 Rosenfeld HM, Landzberg MJ, Perry SB, et al. Balloon aortic valvuloplasty in the young adult with congenital aortic stenosis. Am J Cardiol 1994;73:1112-7.

19 Egito E, Moore P, O'Sullivan J, et al. Transvascular balloon dilation for neonatal critical aortic stenosis: early and midterm results. J Am Coll Cardiol 1997;29:442-7.

20 Vogel $M$, Benson L, Burrows $\mathrm{P}$, et al. Balloon dilatation of congenital aortic valve stenosis in infants and children: short term and intermediate results. $\mathrm{Br}$ Heart J 1989:62:148-53.

21 Witsenburg M, Cromme-Dijkhuis AH, Frohn-Mulder IME, et al. Short- and midterm results of balloon valvuloplasty for valvular aortic stenosis in children. Am J Cardiol 1992;69:945-50.

22 O'Connor BK, Beekman RH, Rocchini AP, et al. Intermediate-term effectiveness of balloon valvuloplasty for congenital aortic stenosis: a prospective follow-up study. Circulation 1991;84:732-8.

23 Shaddy RE, Boucek MM, Sturtevant JE, et al. Gradient reduction, aortic valve regurgitation and prolapse after balloon aortic valvuloplasty in 32 consecutive patients with congenital aortic stenosis. J Am Coll Cardiol 1990;16:451-6. 
24 Galal O Rao PS, Al-FadleyFadel, et al. Follow up results of balloon aortic valuuloplasty in children with special reference to causes of late aortic insufficiency. Am Heart J 1997; 133:418-27.

25 Kuhn MA, Latson LA, Cheatham JP, et al. Management of pediatric patients with isolated valvar aortic stenosis by balloon aortic valvuloplasty. Cathet Cardiovasc Diagn 1996;39:55-61.

26 Borghi A, Agnoletti G, Valsecchi O, et al. Aortic balloon dilatation for congenital aortic stenosis: report of 90 cases (1986-98). Heart 1999;82:e10.

27 Castaneda AR, Richard AJ, John EM, et al. Obstruction of the left ventricular outflow tract. In: Castaneda AR, ed. Cardiac surgery of the neonate and infant. Philadelphia: WB Saunders, 1994:315-32.
28 Somerville J. Aortic stenosis and incompetente. In: Anderson RH, ed. Paediatric cardiology. London: Churchill Livingstone, 1987:977-1000.

29 Zeevi B, Keane JF, Castaneda AR, et al. Neonatal critical aortic stenosis: a comparison of surgical and balloon dilation therapy. Circulation 1989:80:831-9.

30 Ilbawi MN, DeLeon SY, Wilson WR, et al. Extended aortic valvuloplasty: a new approach for the management of congenital valvar aortic stenosis. Ann Thorac Surg 1991;52:663-8.

31 Hossack KF, Neutze JM, Lowe JB, et al. Congenital valvar aortic stenosis: natural history and assessment for operation. Br Heart $J$ 1980;43:561-73.

\section{IMAGES IN CARDIOLOGY}

Pseudo-ventricular tachycardia: electrocardiographic artefact mimicking non-sustained polymorphic ventricular tachycardia in a patient evaluated for syncope

A

n 89 year old woman with a history of hypertension, type 2 diabetes mellitus, and involution depression presented with a syncope of 3-5 minutes duration occurring in a sitting position without associated seizure or other neurological signs. On admission she had signs of mild dehydration, a heart rate of 80 beats $/ \mathrm{min}$ (bpm), and a blood pressure of 140 $80 \mathrm{~mm} \mathrm{Hg}$. The baseline ECG showed sinus rhythm of $87 \mathrm{bpm}$ with left anterior fascicular block and left atrial abnormality. Echocardiography did not reveal any alteration that could possibly explain the syncope. Holter monitor recording revealed two runs consisting of wide complexes of variable morphology apparently consistent with a non-sustained polymorphic ventricular tachycardia (VT), a potential underlying cause of the syncope. Monomorphic premature ventricular complexes also occurred before, in between, and after the wide complex runs. The first wide complex run follows and might be assumed to be initiated by a premature ventricular complex (see fig). However, closer observation of the tracings revealed the continued presence of normal QRS complexes at the cycle length of baseline rhythm within the apparent wide complexes (marked by arrows) and an unstable baseline on the electrogram before the tachycardia events. This resulted in the recognition that the wide complexes were electrocardiographic artefacts. Other signs that indicated the artefactual nature of the tachycardia were: the occurrence of a very early sinus QRS complex at the end of the first tachycardia episode (shown by the last arrow of the second rhythm strip), and the absence of haemodynamic deterioration during the Holter monitoring.

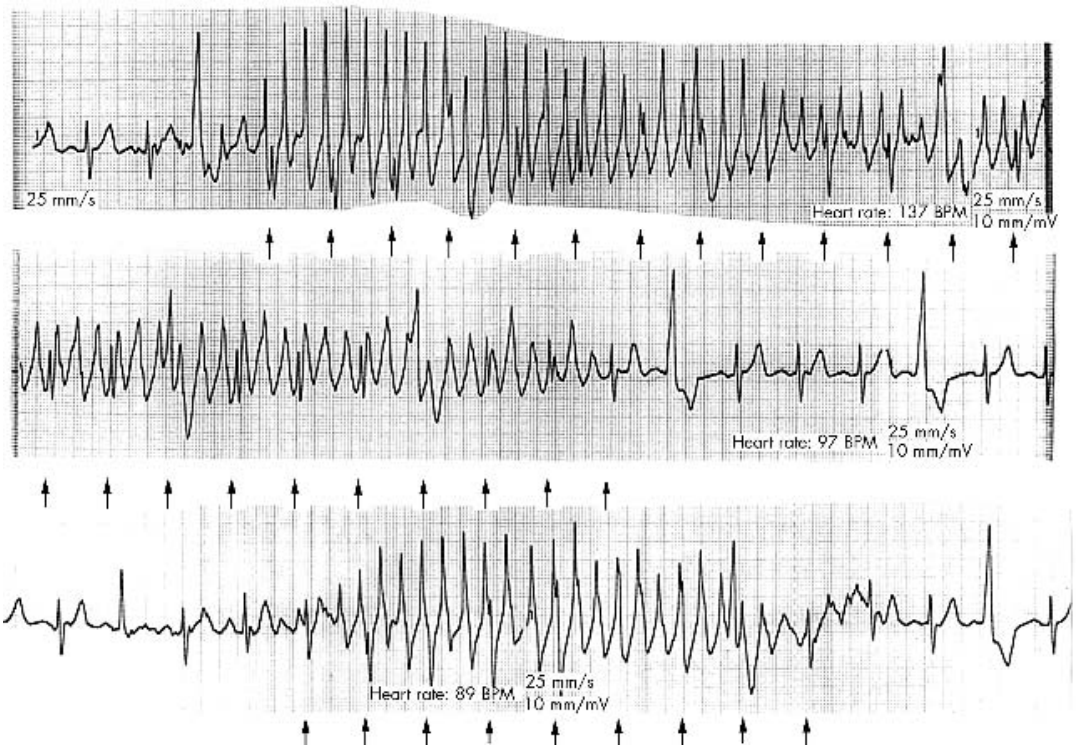

Two polymorphic wide complex tachycardia runs. The upper two strips show the first, wide complex run, the second strip is continuous with the first strip. The bottom strip shows the second wide complex run.

The most likely cause of the electrocardiographic artefact was body movement. An electrocardiographic artefact can closely simulate VT, and even cardiologists not infrequently misdiagnose it as VT, resulting in unnecessary and potentially dangerous medical therapies or interventions.

A Vereckei vereckei@kut.sote.hu 